\title{
Retrieval savings with nonidentical elements: The case of simple addition and subtraction
}

\author{
Jamie I. D. Campbell and Heather Agnew \\ University of Saskatchewan, Saskatoon, Saskatchewan, Canada
}

\begin{abstract}
The identical elements (IE) theory of fact representation (Rickard, 2005) proposes that memorized facts that are composed of identical elements (e.g., $6 \times 8=48$ and $8 \times 6=48$ ) share a common representation in memory, whereas facts with nonidentical elements (e.g., $6 \times 8=48$ and $48 \div 8=6$ ) are represented separately in memory. The IE model has been successfully applied to the transfer of practice in simple multiplication and division, in transition from procedure-based to retrieval-based performance, and in cued episodic recall. In the present article, we examined the effects of practicing simple addition problems (e.g., $3+6=9$ ) on the performance of corresponding subtraction problems $(9-6=3)$, and vice versa. According to IE theory, there should be no transfer of retrieval savings between addition and subtraction facts if performance is based on discrete IE fact representations. Cross-operation response time savings were observed, however, for both small, well-memorized problems (e.g., practice $3+2$, test $5-2)$ and larger problems $(6+8,14-6)$, and they were statistically robust when trials that were self-reported as direct retrieval were analyzed. The transfer of retrieval practice savings between facts with nonidentical elements challenges IE theory as a comprehensive model of transfer in memory retrieval.
\end{abstract}

Practicing a skill virtually guarantees improved performance, but the transfer of practice is often constrained to closely related skills. This observation motivates the identical elements (IE) theory that was first proposed by Thorndike and Woodworth (1901). According to IE theory, transfer depends on practiced and transfer skills' sharing common stimulus-response elements, with transfer increasing as the overlap in identical elements increases. The IE postulate remains an important component in modern theories of skill acquisition and transfer. Indeed, in a review of transfer research, Singley and Anderson (1989, p. 28) concluded, "It seems a fair generalization of the literature to assert that transfer, when it does occur, depends on shared or overlapping representations." A prominent current application of IE principles is the model of number-fact representation that was developed by Rickard (1997) and colleagues (Rickard \& Bajic, 2006; Ricard, Healy, \& Bourne, 1994). Developed initially in the context of memory for simple multiplication and division facts (Rickard et al., 1994), the model has also been applied to transfer effects during transition from algorithmic to retrieval-based performance in a pseudoarithmetic task (Rickard, 1997) and to cued episodic recall (Rickard \& Bajic, 2006). In the present study, we tested whether the IE theory of Rickard (1997) and his colleagues (Rickard \& Bajic, 2006; Rickard et al., 1994) generalizes to simple addition and subtraction (e.g., $3+4=7,7-3=4$ ). If it does, it would provide a comprehensive model of transfer in the domain of arithmetic fact retrieval.

\section{Identical Elements Model of Number-Fact Representation}

Rickard et al. (1994) and Rickard and Bourne (1996) proposed that arithmetic facts composed of identical problem elements (i.e., operands, operator, and answer) share a common long-term memory representation. For example, $6 \times 8=48$ and $8 \times 6=48$ have identical elements and refer to a common representation $[6,8, \times \Rightarrow 48]$. In contrast, inverse multiplication $(6 \times 8=48)$ and division $(48 \div 8=6)$ facts, despite their close conceptual relationship, have nonidentical operand and answer elements and are represented separately. A critical test for the model is that transfer from retrieval practice (i.e., performance savings from strengthening the memory representation) should occur only between identical-element problems. Rickard and Bourne (1996; Rickard et al., 1994) demonstrated that repeatedly practicing specific problems (e.g., $6 \times 8=48$ ) produced savings for identical-element counterparts tested later $(6 \times 8=48$ and $8 \times 6=48)$, but not for problems with nonidentical elements (e.g., $48 \div 8=6$ ).

Subsequent experiments, however, did find transfer between adults' multiplication and division for larger simple divisions with dividends $\geq 25$ (Campbell, 1999; LeFevre \& Morris, 1999; see also Mauro, LeFevre, \& Morris, 2003). Rickard (2005) argued that cross-operation transfer for large divisions did not necessarily contradict IE assumptions, because performance on these problems often is not based on direct retrieval. He proposed a revised IE-r

J. I. D. Campbell, jamie.campbell@usask.ca 
model of multiplication facts that included bidirectional links, with a forward association from factors to products and a reverse association from products to factors $[6,8, \times \Leftrightarrow 48]$. When direct retrieval of a division fact is not possible, the problem may be solved by factoring via the reverse association. For example, the problem $48 \div 6$ would serve as a retrieval cue for the multiplication fact $[6,8, \times \Leftrightarrow 48]$, with the reverse association providing access to the implied quotient, 8 . Division mediated by multiplication would benefit from strengthening the mediating multiplication fact, producing transfer from multiplication practice to corresponding division facts. However, because these cross-operational savings reflect a procedural strategy rather than direct retrieval, they do not violate IE assumptions. Indeed, as is predicted by the IE model, small divisions (e.g., $8 \div 2$ ), which apparently rely primarily on direct retrieval, show little or no savings from strengthening their multiplication counterparts $(2 \times 4=8)($ Campbell, 1999).

\section{Extension of the IE Model to Addition and Subtraction}

If addition and subtraction follow IE principles, the predictions are analogous to those for multiplication and division. Specifically, there should be transfer between identical-element problems within addition (e.g., $4+8$ and $8+4$ ), but no transfer across operations (e.g., $4+8$ and 12 - 4). Campbell, Fuchs-Lacelle, and Phenix (2006) examined the transfer of savings in addition and subtraction with prime and probe problems tested a few trials apart. As is predicted by the IE model, there were probe response time (RT) savings for addition with identical elements (prime $6+9$, probe $6+9$ ) or order change (prime $9+6$, probe $6+9$ ), and there were no savings transferred between addition and subtraction (prime $15-9$, probe $6+9$, or prime $6+9$, probe $15-6$ ). There were unexpected savings between complementary subtractions (prime $15-9$, probe $15-6$ ), which have nonidentical elements, but Campbell et al. concluded that the IE model generally provided a coherent account of transfer between simple addition and subtraction.

Nonetheless, finding no transfer of savings from addition to subtraction is surprising, in retrospect. Adults often report solving large subtractions (e.g., $14-8$ ) by reference to the corresponding addition fact $(6+8=14)$ (LeFevre, DeStefano, Penner-Wilger, \& Daley, 2006; Seyler, Kirk, \& Ashcraft, 2003; see also Campbell, 2008). If addition reference for subtraction often occurred, we would expect recent practice of the addition mediator to speed up subtraction performance. Therefore, to pursue transfer effects in addition and subtraction, we adapted the practice transfer paradigm from Rickard (2005). This paradigm measures problem-specific transfer after extensive practice of specific facts (e.g., practice $2+5$, test $7-2$ ), and it should provide a more sensitive measure than the Campbell et al. (2006) paradigm. Participants received 40 practice blocks of alternating sets of addition and subtraction problems. At test, participants were split into addition-at-test and subtraction-at-test groups, and they received the addition-practiced, subtraction-practiced, and "new" problems. The new problems provided a baseline at test for assessing transfer from the practice phase. Strategy reports were collected during the test phase to identify the use of direct memory retrieval and the use of procedural strategies, such as addition reference.

\section{METHOD}

\section{Participants}

Thirty-two women and 16 men of the ages 18 to 54 years $(M=$ 23.8 years) were randomly assigned to addition and subtraction test conditions ( $n=24$ per group). They either participated for bonus marks in their introductory psychology course at the University of Saskatchewan, or they received $\$ 5$. The experiment was advertised as a study of simple arithmetic skills.

\section{Apparatus}

Instructions and stimuli were displayed by a Microsoft Windows PC on two high-resolution monitors. The experimenter viewed one monitor, and the participant viewed the other from approximately $50 \mathrm{~cm}$ away. To measure the RT, participants wore a lapel microphone that controlled a software clock that was accurate to $\pm 1 \mathrm{msec}$.

\section{Design and Stimuli}

The practice phase included 40 blocks that alternated between 12 addition and 12 subtraction problems, and it was followed by a test phase with 2 blocks of 36 addition or subtraction problems that included the practiced addition, practiced subtraction, and 12 new, unpracticed problems. The first test block was analyzed for transfer effects. The second test block provided a manipulation check on the strategy reports; specifically, because Block 1 practice ought to increase memory strength, the percentage retrieval reported should increase from the first to the second test block.

Three sets of 12 different addition (or corresponding subtraction) problems were constructed, with each set including 2 or 3 problems involving all addends 1 to 9 (see Table 1). There were 6 "small" problems with a sum $\leq 10$ in each set (LeFevre et al., 2006; Seyler et al., 2003), and each set contained two "ties" (e.g., $3+3,7+7$ ). Within each test-operation group, the assignment of sets to practiced addition, practiced subtraction, and new problems was counterbalanced and crossed with addition first or subtraction first during the practice phase. The operand order for each problem (e.g., $3+4 \mathrm{vs.}$ $4+3$, or $7-3$ vs. $7-4$ ) was determined randomly for each participant in the first practice block and used throughout the experiment. The problem order in each block was independently randomized for each participant.

Stimuli appeared horizontally as white characters against a dark background. The two operands in a problem were separated by the operation sign $(+$ or -$)$ with adjacent pairs of spaces. Each character space was approximately $3 \mathrm{~mm}$ wide and $5 \mathrm{~mm}$ high.

\section{Procedure}

Testing took place in a quiet room with an experimenter present. Instructions described the experiment as a test of basic addition and subtraction. The task was to state the correct answer to each problem as quickly and as accurately as possible.

Each block of the practice phase was preceded by a central display of the word ADDITION or SUBTRACTION. The experimenter initiated each block of trials. Prior to each trial, a fixation dot appeared at the center of the screen for $1 \mathrm{sec}$, and then it flashed twice over a 1-sec interval. The problem appeared on what would have been the third flash with the operation sign at fixation. Timing began with problem onset and stopped with the spoken answer. The problem display cleared immediately, which allowed the experimenter to note failures of the microphone. The experimenter typed in the participant's answer; then, the fixation dot for the next trial appeared.

Following the practice phase, the monitor displayed the following instructions for the test phase, which were read aloud by the experimenter: 
Table 1

Problem Sets Used for the Experiment

\begin{tabular}{|c|c|c|c|c|c|}
\hline \multicolumn{2}{|c|}{ Set 1} & \multicolumn{2}{|c|}{ Set 2} & \multicolumn{2}{|c|}{ Set 3} \\
\hline Addition & Subtraction & Addition & Subtraction & Addition & Subtraction \\
\hline \multicolumn{6}{|c|}{ Small Problems } \\
\hline $1+4$ & $5-1$ & $1+5$ & $6-1$ & $1+3$ & $4-1$ \\
\hline $1+8$ & $9-1$ & $1+6$ & $7-1$ & $1+7$ & $8-1$ \\
\hline $2+5$ & $7-2$ & $2+4$ & $6-2$ & $2+3$ & $5-2$ \\
\hline $2+8$ & $10-2$ & $2+7$ & $9-2$ & $4+5$ & $9-4$ \\
\hline $3+4$ & $7-3$ & $3+7$ & $10-3$ & $3+5$ & $8-3$ \\
\hline $2+2$ & $4-2$ & $3+3$ & $6-3$ & $4+4$ & $8-4$ \\
\hline \multicolumn{6}{|c|}{ Large Problems } \\
\hline $3+8$ & $11-3$ & $3+9$ & $12-3$ & $2+9$ & $11-2$ \\
\hline $4+9$ & $13-4$ & $4+8$ & $12-4$ & $4+7$ & $11-4$ \\
\hline $5+7$ & $12-5$ & $5+6$ & $11-5$ & $6+8$ & $14-6$ \\
\hline $6+7$ & $13-6$ & $5+9$ & $14-5$ & $6+9$ & $15-6$ \\
\hline $7+9$ & $16-7$ & $8+9$ & $17-8$ & $7+8$ & $15-7$ \\
\hline $6+6$ & $12-6$ & $7+7$ & $14-7$ & $9+9$ & $18-9$ \\
\hline
\end{tabular}

Note-Table 1 shows one of the two possible orders of each problem (e.g., $3+8$ or $8+3 ; 11-3$ or $11-8)$. One order of each problem was selected at random per participant and was used throughout the experiment. Problems were classified as "small" if the sum or minuend was $\leq 10$; otherwise, the problems were classified as "large."

There will be two blocks of 36 [addition or subtraction] problems. Please answer quickly but accurately. After each problem, indicate how you solved the problem by choosing from among the following possibilities. ADDITION/SUBTRACTION REFERENCE: You used knowledge of the inverse addition or subtraction problem. TRANSFORM: You used knowledge of another related problem. COUNT: You used a strategy based on counting. REMEMBER: You recalled the answer directly without any intermediate steps. OTHER: You used some other strategy or are uncertain.

The experimenter then reviewed each strategy option and offered clarification if requested. The problem display and response timing were the same as in the practice phase. Immediately after the arithmetic answer, the prompt "Strategy Choice" appeared at the center of the screen with the words "add/subtract reference," "transform," "count," "remember," and "other" centered immediately below. The experimenter recorded the strategy reported with a keypress and then entered the stated arithmetic answer. No feedback about speed or accuracy was provided during the experiment.

\section{RESULTS}

\section{All-Trials Analysis}

Table 2 presents mean correct RT and percentage of errors by test operation (addition or subtraction), problem type (practiced addition, practiced subtraction, or new), and problem size (small or large). The $6.1 \%$ of RTs associated with incorrect responses, microphone failures, or more than a $2.5 S D$ from a participant's cell means were discarded. Only effects with $p \leq .05$ are reported. A test operation $\times$ size ANOVA of mean RT for the new problems provided a picture of baseline performance. As in previous research (see Campbell \& Xue, 2001), addition $(1,197 \mathrm{msec})$ was faster than subtraction $(1,478 \mathrm{msec})$ $\left[F(1,46)=6.2, M S_{\mathrm{e}}=306,927, p=.02\right]$, small problems were faster than large problems $[F(1,46)=99.8$, $\left.M S_{\mathrm{e}}=81,293, p<.001\right]$, and the problem-size effect was larger for subtraction $(+786 \mathrm{msec})$ than for addition $(+376 \mathrm{msec})\left[F(1,46)=6.2, M S_{\mathrm{e}}=81,293, p=.001\right]$. The corresponding ANOVA of error percentages for new problems indicated only a main effect of size, owing to more errors on large $(7.3 \%)$ than on small $(3.1 \%)$ problems $\left[F(1,46)=5.2, M S_{\mathrm{e}}=80.5, p=.03\right]$. The critical analyses focused on performance savings relative to new problems in the first posttest block. The labels ${ }_{\mathrm{A}} \mathrm{A}$ and ${ }_{\mathrm{S}} \mathrm{A}$ refer to addition at test after addition and subtraction practice, respectively. ${ }_{\mathrm{A}} \mathrm{S}$ and ${ }_{\mathrm{S}} \mathrm{S}$ are the corresponding labels for subtraction.

RT. RT savings received a test $\times$ practice $\times$ size ANOVA. Mean savings with lower bound $95 \%$ confidence

Table 2

Mean Correct Response Times and Percent Errors at Test by Operation, Problem Type (Practiced Addition, Practiced Subtraction, New), and Problem Size for All Trials

\begin{tabular}{|c|c|c|c|c|c|c|}
\hline \multirow[b]{2}{*}{ Problem Size } & \multicolumn{3}{|c|}{ Addition at Test } & \multicolumn{3}{|c|}{ Subtraction at Test } \\
\hline & Addition & Subtraction & New & Addition & Subtraction & New \\
\hline \multicolumn{7}{|c|}{ Response Time } \\
\hline Small & 868 & 884 & 1,009 & 1,006 & 917 & 1,085 \\
\hline Large & 1,102 & 1,296 & 1,385 & 1,682 & 1,329 & 1,871 \\
\hline \multicolumn{7}{|c|}{ Percent Errors } \\
\hline Small & 0.7 & 4.9 & 2.1 & 2.1 & 1.4 & 4.2 \\
\hline Large & 0.7 & 5.6 & 7.6 & 3.5 & 2.1 & 6.9 \\
\hline
\end{tabular}




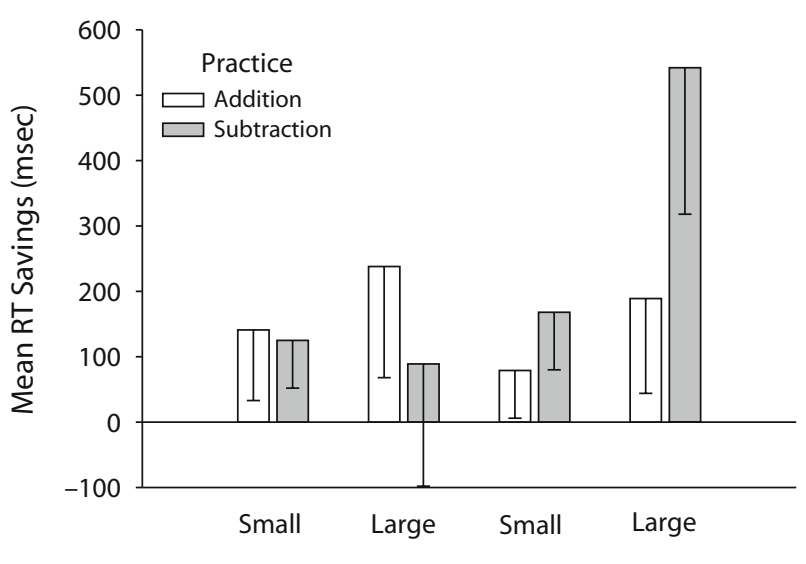

Addition at Test Subtraction at Test

Figure 1. Mean response time (RT) savings (and lower bound $95 \%$ confidence interval) by test operation, practice operation, and problem size.

intervals appear in Figure 1. Savings were greater for large $(276 \mathrm{msec})$ than for small $(128 \mathrm{msec})[F(1,46)=6.5$, $\left.M S_{\mathrm{e}}=160,147, p=.01\right]$ problems. There were also test $\times$ practice $\left[F(1,46)=19.7, M S_{\mathrm{e}}=64,828, p<.001\right]$ and test $\times$ practice $\times$ size $\left[F(1,46)=9.0, M S_{\mathrm{e}}=64,891, p=\right.$ $.004]$ effects. RT savings were greater when the practice and test operations were the same, especially for larger, more difficult problems. Specifically, RT savings were the greatest for large $\mathrm{S}$ S $(542 \mathrm{msec})$, followed by large ${ }_{\mathrm{A}} \mathrm{A}$ (283 msec), with smaller but substantial savings for small ${ }_{\text {A }} \mathrm{A}(141 \mathrm{msec})$ and small $\mathrm{S}(168 \mathrm{msec})$. The RT savings in the present article were much larger than those in Campbell et al. (2006). For example, they found that retesting a subtraction problem after several intervening trials saved $107 \mathrm{msec}$ as compared with $355 \mathrm{msec}$ in the present study for ${ }_{\mathrm{S}} \mathrm{S}$ problems after 40 practice blocks. Extensive practice evidently produced much greater savings.

Most importantly, as Figure 1 shows, there was statistically significant transfer across operations for small ${ }_{S} \mathrm{~A}$ $(125 \mathrm{msec})$, small $\mathrm{A} S(79 \mathrm{msec})$, and large ${ }_{\mathrm{A}} \mathrm{S}(189 \mathrm{msec})$. Overall, average cross-operation RT savings relative to new problems was $121 \mathrm{msec}\left[F(1,46)=17.4, M S_{\mathrm{e}}=\right.$ $40,210, p<.001]$.

Percentage of errors. The corresponding ANOVA of error savings indicated only a test $X$ practice ef- fect $\left[F(1,46)=4.7, M S_{\mathrm{e}}=79.4, p=.04\right]$ : There was evidence of within-operation error savings for both ${ }_{\mathrm{A}} \mathrm{A}$ $[4.2 \%, t(23)=2.3, S E=1.8, p=.03]$ and ${ }_{S} \mathrm{~S}[3.8 \%$, $t(23)=2.0, S E=2.0, p=.06]$ problems, but no crossoperation error savings for either ${ }_{\mathrm{S}} \mathrm{A}[0.3 \%, t(23)=0.2$, $S E=2.0, p=.86]$ or ${ }_{\mathrm{A}} \mathrm{S}[2.8 \%, t(23)=1.6, S E=1.8$, $p=.13$ ] problems.

\section{Retrieval Trials Analysis}

The all-trials analysis demonstrated cross-operation RT savings. According to the IE model, such effects must owe to nonretrieval strategies - for example, solving subtraction by addition reference. Consequently, cross-operation transfer effects should disappear when only retrieval (i.e., remember) trials are analyzed. Mean retrieval RT and errors appear in Table 3. Participants with one or more empty retrieval cells were excluded. For the addition test group, $n=22$ for the RT and error means in Table 3. For the subtraction test group, $n=16$ for the RT analysis and $n=17$ for the error means in Table 3 .

Retrieval RT. Self-reported direct retrieval accounted for $66.1 \%$ of trials (see Table 4). The ANOVA of retrieval RT savings (see Figure 2) mirrored the corresponding all-trials analysis. Retrieval RT savings were greater for large $(242 \mathrm{msec})$ than for small $(102 \mathrm{msec})$ problems $\left[F(1,36)=6.7, M S_{\mathrm{e}}=107,987, p=.01\right]$. There were also test $\times$ practice $\left[F(1,36)=16.0, M S_{\mathrm{e}}=22,820, p<\right.$ $.001]$ and test $\times$ practice $\times$ size effects $[F(1,36)=11.5$, $\left.M S_{\mathrm{e}}=23,838, p=.002\right]$. Retrieval RT savings were the greatest for large ${ }_{S} \mathrm{~S}(396 \mathrm{msec})$, followed by large ${ }_{\mathrm{A}} \mathrm{A}$ $(274 \mathrm{msec})$, and small problems tested in the practiced operation also presented RT savings (113 msec for ${ }_{S} \mathrm{~S}$, $105 \mathrm{msec}$ for ${ }_{\mathrm{A}} \mathrm{A}$ ).

Again, however, there was clear evidence for crossoperation RT savings. Mean savings were $97 \mathrm{msec}$ for small ${ }_{S} \mathrm{~A}, 160 \mathrm{msec}$ for large ${ }_{S} \mathrm{~A}, 92 \mathrm{msec}$ for small ${ }_{\mathrm{A}} \mathrm{S}$, and $137 \mathrm{msec}$ for large ${ }_{\mathrm{A}} \mathrm{S}$. The lower bound of the $95 \% \mathrm{CI}$ shown in Figure 2 indicates that all four cross-operation cells presented evidence of retrieval RT savings. Average cross-operation retrieval RT savings relative to new problems was $123 \operatorname{msec}\left[F(1,36)=18.1, M S_{\mathrm{e}}=30,745, p<\right.$ .001].

Percentage of retrieval errors. Mean retrieval errors appear in Table 3. With respect to error savings, the test operation $\times$ practice operation $\times$ size ANOVA indicated only a triple interaction $\left[F(1,37)=5.0, M S_{\mathrm{e}}=23.3\right.$,

Table 3

Mean Correct Response Times and Percent Errors at Test by Operation, Problem Type (Practiced Addition, Practiced Subtraction, New), and Problem Size for Retrieval Trials Only

\begin{tabular}{|c|c|c|c|c|c|c|}
\hline \multirow[b]{2}{*}{ Problem Size } & \multicolumn{3}{|c|}{ Addition at Test } & \multicolumn{3}{|c|}{ Subtraction at Test } \\
\hline & Addition & Subtraction & New & Addition & Subtraction & New \\
\hline \multicolumn{7}{|c|}{ Response Time } \\
\hline Small & 859 & 863 & 964 & 929 & 906 & 1,020 \\
\hline Large & 939 & 1,051 & 1,213 & 1,269 & 1,011 & 1,407 \\
\hline \multicolumn{7}{|c|}{ Percent Errors } \\
\hline Small & 0.9 & 3.0 & 0.9 & 2.5 & 0.0 & 1.2 \\
\hline Large & 0.9 & 0.0 & 3.0 & 1.2 & 2.6 & 8.3 \\
\hline
\end{tabular}


Table 4

Mean Percentage of Self-Reported Strategies at Test by Operation, Problem Type (Practiced Addition, Practiced Subtraction, New), and Problem Size

\begin{tabular}{|c|c|c|c|c|c|c|}
\hline \multirow[b]{2}{*}{ Problem Size } & \multicolumn{3}{|c|}{ Addition at Test } & \multicolumn{3}{|c|}{ Subtraction at Test } \\
\hline & Addition & Subtraction & New & Addition & Subtraction & New \\
\hline \multicolumn{7}{|c|}{ Remember } \\
\hline Small & 86.1 & 81.9 & 79.2 & 73.6 & 75.7 & 66.0 \\
\hline Large & 66.7 & 58.3 & 59.7 & 45.1 & 61.8 & 38.9 \\
\hline \multicolumn{7}{|c|}{ Addition/Subtraction Reference } \\
\hline Small & 2.1 & 3.5 & 3.5 & 19.4 & 14.6 & 16.7 \\
\hline Large & 4.9 & 2.1 & 3.5 & 29.9 & 20.8 & 25.0 \\
\hline \multicolumn{7}{|c|}{ Count } \\
\hline Small & 9.7 & 12.5 & 12.5 & 6.3 & 8.3 & 13.9 \\
\hline Large & 9.0 & 15.3 & 17.4 & 10.4 & 8.3 & 14.6 \\
\hline \multicolumn{7}{|c|}{ Transform } \\
\hline Small & 2.1 & 1.4 & 3.5 & 0.7 & 0.7 & 1.4 \\
\hline Large & 15.3 & 16.7 & 13.9 & 11.1 & 8.3 & 11.8 \\
\hline \multicolumn{7}{|c|}{ Other } \\
\hline Small & 0.0 & 0.7 & 1.4 & 0.0 & 0.7 & 2.1 \\
\hline Large & 4.2 & 7.6 & 5.6 & 3.5 & 0.7 & 9.7 \\
\hline
\end{tabular}

$p=.03]$. A perusal of Table 3 reveals a complex pattern with no obvious interpretation, particularly since $t$ tests provided no statistical evidence of error savings in any of the eight cells (smallest $p=.10$ ).

\section{Strategy Reports}

Table 4 presents the mean percentage of reported use of each strategy. The overall reported rates were $66.1 \%$ remember (i.e., retrieval), $12.2 \%$ reference, $11.5 \%$ count, $7.2 \%$ transform, and $3.0 \%$ other. Practice should strengthen the number-fact representation and increase retrieval (Campbell et al., 2006). Consistent with this assertion, reported retrieval for new addition problems increased from $69.4 \%$ in Test Block 1 to $79.2 \%$ in Test Block 2; reported retrieval for new subtraction problems increased from $52.4 \%$ to $61.8 \%$ across test blocks.

A test $\times$ practice $\times$ size ANOVA of retrieval savings (i.e., percentage increase in reported "remember" relative to new problems in Test Block 1) indicated a test $\times$ practice effect $\left[F(1,36)=16.0, M S_{\mathrm{e}}=182.9, p<.001\right]$, which reflected greater retrieval savings when test and practice operations were the same $(+11.6 \%)$ rather than with an operation change $(+3.8 \%)$. As Table 4 shows, the test $\times$ practice $\times$ size interaction $\left[F(1,36)=6.0, M S_{\mathrm{e}}=176.8\right.$, $p=.02]$ reflected especially high retrieval savings for large ${ }_{\mathrm{S}} \mathrm{S}$ problems $(+22.9 \%) \cdot{ }_{\mathrm{A}} \mathrm{S}$ problems, however, also presented significant retrieval savings $[+6.9 \%, t(23)=$ $2.1, S E=2.8, p=.02]$. Retrieval savings for ${ }_{\mathrm{A}} \mathrm{S}$ problems occurred, despite addition practice promoting the addition reference strategy for subtraction: An analysis of reference strategy "savings" indicated a test $\times$ practice interaction $\left[F(1,36)=5.6, M S_{\mathrm{e}}=83.3, p=.02\right]$, which occurred because addition practice tended to increase addition reference for the corresponding subtraction problem $(+3.8 \%)$, whereas subtraction practice tended to decrease reported reference for subtraction $(-3.1 \%)$, and whereas the use of subtraction reference for addition was infrequent and unaffected by the practiced operation. Apart from these results, increased retrieval relative to new problems reflected small decreases in the reported use of the three other strategies (Table 4).

\section{DISCUSSION}

The representational assumptions of the IE model (Rickard, 2005; Rickard \& Bourne, 1996) predict no retrieval-based transfer between addition and subtraction. Transfer mediated by a procedural strategy, however, does not contradict IE assumptions. For example, solving subtraction (e.g., $13-5=$ ?) by intentional reference to the corresponding addition fact (i.e., $5+8=13$ ) would

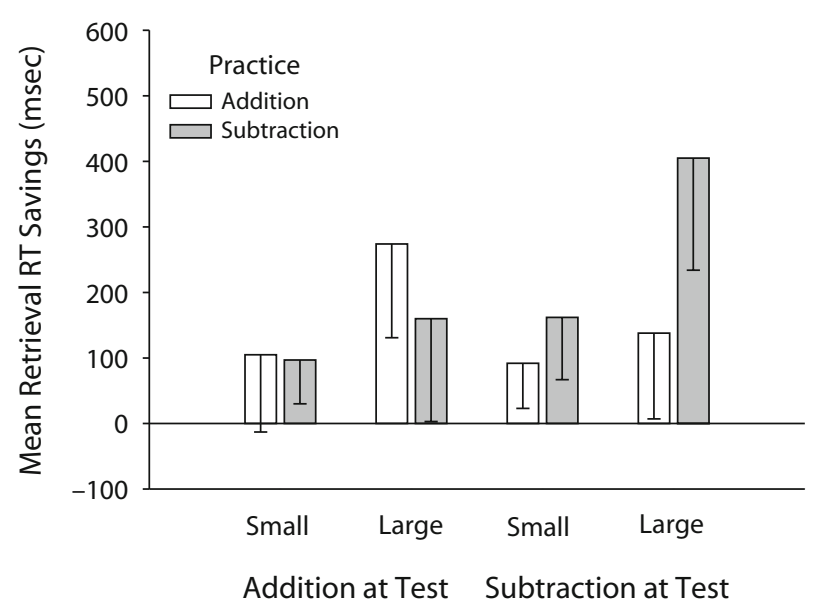

Figure 2. Mean retrieval response time (RT) savings (and lower bound $95 \%$ confidence interval) by test operation, practice operation, and problem size. 
be facilitated by strengthening that addition fact through practice. Such transfer does not violate the model's representational assumptions, because it arises through a procedural strategy rather than by direct memory retrieval. Indeed, participants in the present study reported substantial use of addition reference, especially for large subtractions, and addition practice promoted addition reference reports at test. Thus, the addition-to-subtraction transfer in Table 2 would be attributable, in part, to procedural transfer, and does not necessarily contradict the model.

Other features of the data are more challenging for an IE model. Figure 1 shows that small $\mathrm{S}$ A problems presented significant RT savings of $125 \mathrm{msec}$, which was similar to the $141 \mathrm{msec}$ observed for ${ }_{\mathrm{A}} \mathrm{A}$ problems. Thus, for example, latency to answer $2+5$ benefitted as much from practicing $7-2$ as it did from practicing $2+5$. The reported use of subtraction to solve small addition problems was less than $3 \%$ (Table 4 ), making it unlikely that ${ }_{\mathrm{S}} \mathrm{A}$ savings reflected the use of a subtraction reference. Furthermore, the RT savings for small ${ }_{S} \mathrm{~A}$ problems remained robust when only retrieval trials were analyzed. Indeed, the analysis of retrieval RT savings (Figure 2) indicated significant cross-operation savings in both directions for both small and large problems. Small ${ }_{\mathrm{A}} \mathrm{S}$ problems also presented significant retrieval savings at test relative to new small subtractions $(+8 \%)$. Thus, practicing $2+5$, for example, increased the probability of using direct retrieval for $7-2$, and this increase was similar in magnitude to ${ }_{S} S$ problems $(+10 \%)$. Campbell et al. (2006) also found that addition practice promoted subtraction retrieval. The IE theory, in which identity is defined by common stimulusresponse elements, has no mechanism to explain retrievalbased transfer of savings between subtraction and addition problems. Overall, cross-operation savings in retrieval RT $(123 \mathrm{msec})$ were half as large as same-operation retrieval RT savings $(237 \mathrm{msec})$, indicating that practice of the identical problem conferred a substantial transfer advantage as compared with cross-operation practice. Nonetheless, cross-operation savings were statistically robust and observed consistently in all four cross-operation cells.

\section{Transfer With Nonidentical Elements}

The transfer of retrieval savings between inverse addition and subtraction problems strongly implies shared representation, despite nonidentical problem elements (i.e., different operands and answers). This implication apparently contradicts the transfer principles ensconced in Rickard's (2005) IE model. Nonetheless, the transfer predictions of the IE model appear to hold for multiplication and division fact retrieval (Rickard \& Bourne, 1996); consequently, we must ask what is unique about addition and subtraction that enables the transfer of retrieval savings between nonidentical facts. Both imaging and neuropsychological data suggest that addition and subtraction, but not multiplication, often utilize a semantic quantity representation (Dehaene, Molko, Cohen, \& Wilson, 2004). Semantic mediation for simple addition and subtraction might occur in parallel with IE fact retrieval and provide a mechanism for nonidentical transfer. Repeated practice manipulating a particular combination of quantities (e.g., 3,4 , and 7) in the context of one operation might generalize to, and facilitate, another manipulation that relates those quantities, giving rise to cross-operation transfer for addition and subtraction. ${ }^{1}$ With extensive practice, semantic mediation could become automated - in effect, a component of direct retrieval. The development of a shared quantity structure could emerge through the repeated application of addition reference for subtraction, which begins early on in learning subtraction (Barrouillet, Mignon, \& Thevenot, 2008). As the practice of subtraction by addition reference accumulates, the evolving IE and quantity-based retrieval structure for a subtraction fact may become integrated with the addition fact via the common quantity structure. Retrieving and processing the common quantity representation for either operation would strengthen the links among those quantities and facilitate semantic mediation for either operation, giving rise to both within- and cross-operation transfer. Greater savings with identical repetition than with an operation change would owe to the strengthening of the discrete, operation-specific IE representations.

\section{Conclusions}

Retrieval savings between inverse addition and subtraction problems indicate that the IE model is not a comprehensive theory of transfer in number-fact retrieval. The model appears to apply to multiplication, factoring, and division (Rickard, 2005; Rickard \& Bourne, 1996), but the present results for addition and subtraction demonstrated retrieval savings between problems with nonidentical elements. Semantic mediation of retrieval for additionsubtraction but not for multiplication-division might explain why the IE model accurately predicts transfer for the latter operations but not the former; further research is necessary to characterize the mechanisms of retrieval savings between addition and subtraction facts. Understanding how and why memory and learning processes differ fundamentally for addition-subtraction versus multiplication-division could have important theoretical and pedagogical implications both for arithmetic and for transfer theory in general.

\section{AUTHOR NOTE}

The present research was supported by a grant from the Natural Sciences and Engineering Research Council of Canada. Address correspondence to J. I. D. Campbell, Department of Psychology, University of Saskatchewan, 9 Campus Drive, Saskatoon, SK, S7N 5 A5 Canada (e-mail: jamie.campbell@usask.ca).

\section{REFERENCES}

Barrouillet, P., Mignon, M., \& Thevenot, C. (2008). Strategies in subtraction problem solving in children. Journal of Experimental Child Psychology, 99, 233-251. doi:10.1016/j.jecp.2007.12.001

CAmpbell, J. I. D. (1999). Division by multiplication. Memory \& Cognition, 27, 791-802.

Campbell, J. I. D. (2008). Subtraction by addition. Memory \& Cognition, 36, 1094-1102. doi:10.3758/MC.36.6.1094

Campbell, J. I. D., Fuchs-Lacelle, S., \& Phenix, T. L. (2006). Identical elements model of arithmetic memory: Extension to addition and subtraction. Memory \& Cognition, 34, 633-647. 
Campbell, J. I. D., \& Xue, Q. (2001). Cognitive arithmetic across cultures. Journal of Experimental Psychology: General, 130, 299-315. doi:10.1037/0096-3445.130.2.299

Dehaene, S., Molko, N., Cohen, L., \& Wilson, A. J. (2004). Arithmetic and the brain. Current Opinion in Neurobiology, 14, 218-224. doi:10.1016/j.conb.2004.03.008

LeFevre, J.-A., DeStefano, D., Penner-Wilger, M., \& Daley, K. E. (2006). Selection of procedures in mental subtraction. Canadian Journal of Experimental Psychology, 60, 209-220. doi:10.1037/ cjep2006020

LeFevre, J.-A., \& Morris, J. (1999). More on the relation between division and multiplication in simple arithmetic: Evidence for mediation of division solutions via multiplication. Memory \& Cognition, 27, 803-812.

Mauro, D. G., LeFevre, J.-A., \& Morris, J. (2003). Effects of problem format on division and multiplication performance: Division facts are mediated via multiplication-based representations. Journal of Experimental Psychology: Learning, Memory, \& Cognition, 29, 163-170. doi:10.1037/0278-7393.29.2.163

RICKARD, T. C. (1997). Bending the power law: A CMPL theory of strategy shifts and the automatization of cognitive skills. Journal of Experimental Psychology: General, 126, 288-311. doi:10.1037/0096 $-3445.126 .3 .288$

RickARD, T. C. (2005). A revised identical elements model of arithmetic fact representation. Journal of Experimental Psychology: Learning, Memory, \& Cognition, 31, 250-257. doi:10.1037/0278 $-7393.31 .2 .250$

RickARD, T. C., \& BAJIC, D. (2006). Cued recall from image and sen- tence memory: A shift from episodic to identical elements representation. Journal of Experimental Psychology: Learning, Memory, \& Cognition, 32, 734-748. doi:10.1037/0278-7393.32.4.734

Rickard, T. C., \& Bourne, L. E., JR. (1996). Some tests of an identical elements model of basic arithmetic skills. Journal of Experimental Psychology: Learning, Memory, \& Cognition, 22, 1281-1295. doi:10.1037/0278-7393.22.5.1281

Rickard, T. C., Healy, A. F., \& Bourne, L. E., Jr. (1994). On the cognitive structure of basic arithmetic skills: Operand order, symbol, and operation transfer effects. Journal of Experimental Psychology: Learning, Memory, \& Cognition, 20, 1139-1153. doi:10.1037/0278 $-7393.20 .5 .1139$

Seyler, D. J., Kirk, E. P., \& Ashcraft, M. H. (2003). Elementary subtraction. Journal of Experimental Psychology: Learning, Memory, \& Cognition, 29, 1339-1352. doi:10.1037/0278-7393.29.6.1339

Singley, M. K., \& Anderson, J. R. (1989). The transfer of cognitive skill. Cambridge, MA: Harvard University Press.

Thorndike, E. L., \& Woodworth, R. S. (1901). The influence of improvement in one mental function upon the efficiency of other functions. Psychological Review, 8, 247-261. doi:10.1037/h0074898

\section{NOTE}

1. We thank Tim Rickard for raising this theoretical approach.

(Manuscript received December 11, 2008; revision accepted for publication May 13, 2009. . 